International Journal of Child, Youth and Family Studies (2013) 3.1: 409-432

\title{
DELIBERATION MODELS FEATURING YOUTH PARTICIPATION
}

\section{Denise Bulling, Lyn Carson, Mark DeKraai, Alexis Garcia, and Harri Raisio}

\begin{abstract}
There is a growing trend among developed countries to increase the participation of youth in societal and institutional decision-making. The challenge is to move away from an illusion of participation (tokenism) to genuine youth influence. This article transfers knowledge of a relatively new theory to the fields of youth engagement and community development. We pose deliberative democracy as a model to build bridges between youth and decision-makers. This concrete approach offers a platform for youth and adults to engage in a learning process as equal citizens and proactive leaders. Deliberative democracy can be understood as an umbrella term for different models of public deliberation. These models attempt to create carefully detailed conditions for increasing the legitimacy of decisions made through deliberation. Deliberative models that feature youth participation include youth juries, dialogue days between young people and decision-makers, and adult-youth participatory forums where the youth voice is usually a minority. We explore the role of relationships, collaboration, and leadership in generating democratic spaces for the inclusion of youth in policy formation and reform. The challenges associated with engaging youth are discussed along with examples of models from Australia, Finland, Canada, and the United States that promote effective youth engagement.
\end{abstract}

Keywords: deliberative democracy, decision-making, collaborative governance, learning processes, policy reform, youth engagement

Acknowledgements: For their contributions or editing, the authors wish to thank Tarik Abdel-Monem, Stacey Hoffman, and Ryan Lowry.

Corresponding author: Denise Bulling, Ph.D., Public Policy Center, University of Nebraska, 215 Centennial Mall South, Suite 401, PO Box 880228, Lincoln, Nebraska, USA, 68588-0228. Email: dbulling@nebraska.edu 
International Journal of Child, Youth and Family Studies (2013) 3.1: 409-432

The authors have requested alphabetical listing:

Denise Bulling, Ph.D. is a Senior Research Director at the University of Nebraska Public Policy Center, 215 Centennial Mall South, Suite 401, Lincoln, Nebraska, USA, 68508.

E-mail: dbulling@nebraska.edu

Lyn Carson, Ph.D. is a Professor at the University of Sydney Business School, Merewether Building, City Road, University of Sydney, New South Wales, 2006, Australia.

E-mail: lyn.carson@sydney.edu.au

Mark DeKraai, Ph.D., J.D. is a Senior Research Director at the University of Nebraska Public Policy Center, 215 Centennial Mall South, Suite 401, Lincoln, Nebraska, USA, 68508. E-mail: mdekraai@nebraska.edu

Alexis Garcia, M.A. is a consultant and researcher on the subjects of dialogue, change management, and democratic and inclusive governance in Montreal, Quebec, Canada. E-mail: garcia.alexis.1978@gmail.com

Harri Raisio, Ph.D. is an Assistant Professor in Social and Health Management at the University of Vaasa, Yliopistonranta 10, 65101 Vaasa, Finland.

E-mail: harri.raisio@uwasa.fi

There is a growing effort in developed countries to increase the participation of youth in political and institutional decision-making. The challenge is to steer away from tokenistic participation and engender genuine youth influence (Feldmann-Wojtachnia et al., 2010). The goal of these efforts is to develop a real, measurable impact of the input of youth.

Some have posited that deliberative dialogue and decision-making among youth is limited by their lack of knowledge and experience with social or policy issues worthy of deliberation, or that they underestimate potential negative consequences of either personal decisions or policy choices (Huber, Frommeyer, Weisenbach, \& Sazama, 2003; Ryan, 2010; Wolff \& Crockett, 2011). On the other hand, proponents of involving youth in deliberation assert that youth are too often excluded from important decision-making activities, which contributes to feelings of marginalization and undermines notions of deliberative democracy (Frank, 2006; Young, 2000). There are various forms of deliberative activities and forums targeting youth, including youth engagement councils in the United Kingdom (Matthews, 2010; Wyness, 2009), youth study circles (Wulff, 2003), and online deliberation (Edelmann, Krimmer, \& Parycek, 2008; Scherer, Neuroth, Schefbeck, \& Wimmer, 2009; Wells, 2010). Practitioners of deliberative discussion and engagement have great interest in using digital and networked media as vehicles and forums for engaging youth (Bennett, Wells, \& Freelon, 2009; Levine, 2007a; Olsson, 2007; A. Von Burg, R. Von Burg, Mitchell, \& Louden, 2012). In addition to enhancing youth-adult engagement and improving public policy, these approaches may have an added benefit of leading to the development of civic habits and attitudes among youth (Levine, 2007b; McLeod, 2000). 
International Journal of Child, Youth and Family Studies (2013) 3.1: 409-432

To ensure youth can productively engage in institutional decision-making, a variety of efforts have been made to enhance their understanding of policy issues, develop the skills needed to engage in effective dialogue, and create opportunities for youth engagement in decisionmaking processes. For example, schools routinely offer classes or implement programs designed to educate students about civic knowledge, responsibilities, and skills (Pasek, Feldman, Romer, \& Jamieson, 2008; Syvertsen et al., 2009; Youniss, 2011). Service-learning programs and other activities that promote linking students with community activities and issues have also become commonplace (Hart \& Donnelly, 2007; Morgan \& Streb, 2001; Waldstein \& Reiher, 2001). Specific curricula focusing on developing deliberative skills have been offered in classroom environments (Battistoni, 2004; Peng, 2000; Rubin, 2007). Projects have also focused more intentionally on involving youth in forums outside of school-based programming to promote civic engagement and discussion (Ferman, 2005; Mohamed \& Wheeler, 2001).

One form of public participation relying on effective dialogue skills of citizens is built around a normative theory called deliberative democracy (Chambers, 2003). Deliberative democrats strive to create carefully detailed conditions for increasing the legitimacy of decisions created through deliberation. This article examines deliberative democracy as it pertains to youth participation by providing real world examples of its implementation.

A brief introduction to deliberative democracy is offered, and then four different examples of deliberative youth participation are presented, each highlighting different characteristics of deliberative democracy. They include deliberation solely for young people, deliberation between young people and decision-makers, and mixed-age deliberations. These four cases are summarized in relation to the three criteria of deliberative democracy (inclusion, deliberation, and influence) to highlight the prospects and challenges of deliberative youth participation (Carson \& Hartz-Karp, 2005).

\section{Defining Deliberative Democracy}

Practitioners use a variety of terms to describe public engagement processes based on the theory of deliberative democracy including civic engagement, community engagement, public participation, or public deliberation. Deliberative democracy is understood as a form of democracy that values discussion, reflection, and consideration over simply voting (Chambers, 2003). At its best, this form of engagement should be inclusive of stakeholder populations, meaning that those participating in the deliberation should represent different societal views as much as possible; it should be deliberative, to allow participants to thoroughly consider the topic and weigh different options and the values underlying decisions; and it should have influence, to be genuinely collaborative with decision-makers - in other words it should influence the policy outcome (Carson \& Hartz-Karp, 2005).

Deliberative democratic theory pays particular attention to deliberation, or discussion where one is "to be truthful in what one says, to respect the arguments of others, to give good reasons for one's own arguments, and to be open to changing one's position by the force of the better argument” (Steiner, 2012, p. 3). Deliberation would then take place in an ideal situation, defined by Habermas (1999) as everyone having equal opportunity to participate in public discussion; where all participants can present their own views and arguments; and where the 
International Journal of Child, Youth and Family Studies (2013) 3.1: 409-432

power or status of the participant is irrelevant and the merits of the argument prevail. Deliberative democracy has developed beyond its idealistic, classical form and has been applied to real world decision-making (Elstub, 2010; Bächtiger, Niemeyer, Neblo, Steenbergen, \& Steiner, 2010; Mansbridge et al., 2010).

Deliberative democracy is understood to produce two kinds of value: instrumental and expressive (Gutmann \& Thompson, 2004). Instrumentally, public deliberation is seen as a tool leading decision-makers to achieve good and justifiable decisions. Such instrumental purposes can be more specifically understood as informing and legitimizing policy and, in some cases, freeing a paralyzed policy process. As a more expressive purpose, public deliberation is seen to revitalize democracy. Public deliberation can help citizens move toward public judgment on specific issues; promote a healthier democratic culture and more capable citizenry; build community; and catalyze civic action (Friedman, 2006). However, deliberative democracy is not without challenges: for example, ensuring inclusiveness of participants (Clifford, 2012); deciding how to conduct the deliberation when participants speak different languages (Addis, 2007); minimizing the use of power and polarization of preferences in deliberation (Sanders, 1997; Sunstein, 2003); and scaling up the applications of deliberative democracy (Friedman, 2006; Mansbridge et al., 2012).

Various methods attempt to deliver the three ideals of deliberative democracy: inclusiveness, deliberation, and influence (Carson \& Hartz-Karp, 2005). Collectively these methods are described as mini-publics and include 21st century town meetings, citizens' juries, planning cells, consensus conferences, and deliberative polling. They differ, for example, in the length of the events (generally from 2 to 5 days) and in the number of participants (from a dozen to even hundreds or thousands of deliberators), and the structure of the deliberations, but what connects these approaches are created conditions leading to deliberative processes of high quality (Fung, 2003).

Mini-publics are part of the wider set of deliberative methods used in democratic systems (Dryzek, 2010; Mansbridge et al., 2012). Ideally, systems become stronger when all the different kinds of deliberative mechanisms, and relationships among them, are supported. Thus, the diversity of these different deliberative mechanisms should be celebrated and the connections between them fostered (Hendriks, 2006). Deliberative youth participation is one of these particular mechanisms.

\section{Applications of Deliberative Youth Participation}

Applications of deliberative democracy focused solely on young people are still few in number (Carson, Sargant, \& Blackadder, 2004; Eskelinen et al., 2012; Raisio, Ollila, \& Vartiainen, 2012). Often these applications are traditional mini-publics that strive to include the whole society in miniature. Whole society in this case often means those citizens who have reached the voting age, which in many countries is 18 years. Four examples of deliberative youth participation are presented here. Each case example includes the three criteria of deliberative democracy: inclusion, deliberation, and influence. A brief review of these criteria and the application to the four cases sets the stage for understanding how each fits the deliberative model. 
International Journal of Child, Youth and Family Studies (2013) 3.1: 409-432

Ideal deliberative processes are inclusive, with different societal views represented. Commonly, stratified random-sampling is applied (Carson \& Martin, 1999). This is the case with one of the examples, the Australian youth jury. The United States deliberation on pandemic influenza set a goal of attracting participants who represented their communities, but did not use random selection. Finland's Dialogue Day and Canada's deliberation in the Indigenous community applied a more open method of participant recruitment. Of the four case studies, deliberation on pandemic influenza can be identified as a traditional mini-public, that is, a deliberative model that selects participants from amongst the entire population. Young people represent then only one age cohort in the deliberation. Canada's deliberation in the Indigenous community resembles enclave deliberation where participants share a "structural location in relation to the issue” (Karpowitz, Raphael, \& Hammond, 2009, p. 582). Individuals who are affiliated with the topic of deliberation are chosen to participate, in this case people from different parent and youth groups, and community organizations. The youth jury and Dialogue Day, on the other hand, can be identified more as enclaves of shared identity or as sectoral minipublics (Raisio \& Carson, in review). Even though young participants share their thoughts with expert witnesses and decision-makers, most of the time they deliberate amongst themselves.

The quality of deliberation can be considered as high in all the case studies. First, skilled facilitation was used ensuring that all the young participants were able to voice their opinions and be heard. A safe space for deliberation was created and participants had time and resources to consider the topics of the deliberations deeply. From the four hours of the deliberation in the Indigenous community to three days of deliberation in the youth jury, participants were able to develop their views. Also, relevant information was given to participants. For example, in the deliberation on pandemic influenza, in the youth jury, and in Dialogue Day information packages and presentations by experts or panels of experts were used.

Influence of deliberation is critical for the success of deliberative youth participation. Without influence the risk is that participation will be seen as tokenism. As a result, cynicism will increase and willingness to participate decrease (Segall, 2005). Participants in all the case studies experienced the powerful sensation of being heard and having their views listened to and valued. The knowledge of participants increased through participation in these deliberative events. Additionally, the experience of the deliberation in the Indigenous community shows signs of social healing, "a moment of overcoming isolation and becoming whole” (Wilson, 2009).

Instrumental value generated by the deliberative events, that is, the actual influence on policy-making, is difficult to quantify. However, all four case studies applied methods that increase the possibility for policy impact and thus decrease the risk of tokenism. In the youth jury the project team committed themselves to assisting participants to follow through with the recommendations of the jury. Similarly in the deliberation on pandemic influenza, the project team traced the use of information gained from the deliberation by interviewing key decisionmakers. Dialogue Day ended in a facilitated discussion between young people and relevant decision-makers, thus allowing the latter to commit to acting on the suggestions made by the young participants. Finally, deliberation in the Indigenous community shows how important it is 
International Journal of Child, Youth and Family Studies (2013) 3.1: 409-432

to include relevant stakeholders, such as the chief, from the beginning, and to co-design the deliberative processes collaboratively.

We recommend that readers of the following case studies look for elements of inclusiveness, quality processes, and influence of each deliberative model.

\section{Australia's First Youth Jury ${ }^{1}$}

In 2003 Australia's first youth jury was convened in Parramatta, near Sydney. It was, the organizers believe, the world's first youth jury to be convened by young people themselves. This case study demonstrates how young people can redesign a mini-public to suit the needs of youth. It also demonstrates how inclusion, deliberation, and influence can be achieved.

The youth jury project emerged from a university course, which was taught by the second listed author of this article, at the University of Sydney (Carson, 2010). The author helped the team apply for funding to transfer their classroom experience to an intractable community problem: racial stereotyping of ethnic groups. Once government funds were granted, the author stepped out of the picture. Members of the project team were encouraged to make their own decisions within a supportive framework. They were offered training in facilitation techniques and access to expert practitioners whenever they needed additional input. The team was largely self-sufficient but used adults as co-administrators and mentors, to test their thinking and strengthen their practice.

The eight people who comprised the project team were almost all in their final year of an undergraduate degree, around 20 years of age, and interested enough in the political landscape to be studying a course within the discipline of political science. In the course mentioned above, they convened a citizens' jury within the university but were hungry to try it in the real world. Eight nervous young people embarked on the organization of this project, which was a youth version of a citizens' jury. Eight confident young people completed it, and 17 even younger people were selected as juror participants. The 17 jurors were 16 to 17 years of age and still in high school.

This project was important not only because it was the first youth jury to be conducted in Australia and the world's first youth jury to be conducted by young people themselves; it was also special because of the age of the people being consulted, the age of the people doing the consulting, the innovative deliberative method being used, and the bold adaptations that occurred in the hands of the young organizers and participants.

Four challenges created context for the youth organizers. First, students had learned the theory of deliberative democracy, believed in the value of community engagement (the practical expression of the theory), and wanted to put theory into practice. Second, a city (Parramatta) in metropolitan Sydney was experiencing problems in relation to its diverse community and this was reflected in the media's controversial conflation of young people with crime and ethnicity. Parramatta city council was looking for ways to empower its young people. Third, the young

\footnotetext{
${ }^{1}$ See Carson (2010) for initial publication details of this case study.
} 
people from ethnic communities in the Parramatta area were like most young people everywhere - denied a voice in public debates and policy-making on controversial issues. They were eager to be heard. Finally, the Australian government was offering grants under its Living in Harmony program to address the spreading conflict and intolerance that exists in Australia because of racist attitudes to its multicultural population. The project addressed all four challenges in a number of innovative ways.

The project team successfully applied for funds to conduct a youth jury along the lines of U.S. citizens' juries that were initiated by Ned Crosby and the Jefferson Center in the 1970s (Crosby, 2003). Australian citizens' juries have adapted this process, most often reducing the time (typically to two or three days) and number of participants (12 to 20). They have rarely included a dynamic web presence. The citizens' jury method was chosen because the team wanted to maximize participants' diversity and provide a deliberative space in which consensus could be built through critique. A citizens' jury, and therefore a youth jury, enables participants to wrestle with complexity, having heard expert speakers, in the company of a skilled, independent facilitator who ensures a healthy group process (Carson, 2003).

The project team conducted a preliminary survey to establish the issues that were uppermost for the community. They then called for expressions of interest from 16- to 17-yearold youth and actively sought young people whose voices would typically remain unheard. The project team used a variety of selection methods (random selection, surveys, and face-to-face interviews) to maximize the diversity of participants. From this pool of 73 applicants, 17 young people were randomly selected to participate as jurors.

Three introductory sessions were held during which the jurors were informed about the youth jury process. An environment conducive to sharing and respecting one another's opinions and ideas was developed. Jurors were also exposed to the skills of strategic questioning (Peavey, 2005). These sessions prepared the jurors for the deliberative demands of the three-day youth jury. The jurors decided to focus their attention on the media's portrayal of ethnic communities and the broader community's response to this portrayal. The youth jury brought together presenters who knew a great deal about the topic (from the media, multicultural organizations, academia, and so on). The jurors listened and asked questions and became increasingly more informed, enabling them to ask probing, intelligent questions of the presenters and each other when they later convened to deliberate.

The youth jury deviated from a typical Australian citizens’ jury in a number of ways. The project team was committed to giving young people a say about issues that were important to them and they were sufficiently empowered to redefine the three-day jury process to suit their own needs. Jurors were encouraged to set the agenda and control the process. This level of control by participants is unusual for a citizens' jury.

Independent, skilled facilitation is essential for a citizens' jury to ensure productive group activity without unhelpful dominance or timidity. The project team developed a system for rotating three moderators during the jury process - constantly supporting each other and reflecting together on their practice. This was unusual as a citizens' jury usually employs a single facilitator. The process was extremely flexible to accommodate the process needs of young 
International Journal of Child, Youth and Family Studies (2013) 3.1: 409-432

participants. This often meant that painstakingly created plans were discarded so that the physical, intellectual, and emotional needs of participants could be better served.

The project team developed briefing documents that sought to cover all viewpoints on the topic selected by jurors. When the jurors were demonstrating a single, shared perspective, contrary perspectives were gathered to encourage the jurors to test their opinions. The jurors chose informed presenters who they believed would provide them with the most useful information. This is typical for a citizens' jury. However, in a further innovation, they invited expert speakers to interact through a panel of speakers, rather than having their words unchallenged by jurors or other speakers. In other words, instead of emulating a citizens' jury which can sometimes distance the jurors from the speakers (because everyday citizens can be intimidated by experts) and experts from each other (because they speak alone to the jurors and rarely debate each other in front of the jurors), the youth jury created an environment of internal challenge and speculation.

The project team also made a commitment to the jurors that they would assist them in following through with their recommendations, promising to act as mentors to each of the highly motivated jurors. This is an unusual extension of the citizens' jury process - to have the jurors pursue their claims beyond the life of the consultation process. Further, all those young people who applied but were not randomly selected as jurors were contacted and given information about possibilities for community engagement in their local area.

The recommendations that emerged from the jury were thoughtful and strategic and were handed to the local Parramatta community during a public forum. The public forum was as innovative as the youth jury because it used a process of speed dialogue to engage all participants in the next stage of the project: enacting the recommendations. Speed dialogue (as students had named it) was a micro-process that had been experimented with during the university course. It was modelled on the World Café process (http://www.theworldcafe.com) and enabled participants to move quickly and often from group to group, to deepen their conversations. Later, members of both the project team and the jury met the Premier of New South Wales and on a number of other occasions project team members were asked to speak about their experiences and the innovative process they enacted, often for the benefit of professional public participation practitioners.

This project fulfilled the ideals of deliberative democracy. Evidence of young people's enthusiasm for active citizenship was provided by the number who completed participation forms, indicating their willingness to participate in the youth jury. The 15 who eventually participated in the youth jury took on the challenge of seeing their recommendations enacted. The project has been mentioned in state parliament and has received wide media coverage. The youth jury has been publicly recognized by state and federal members of parliament and by numerous organizations, such as local police and the chamber of commerce. Members of the project team have been invited to address school groups and community organizations and to be interviewed on radio.

The project had positive outcomes for all concerned: Members of the project team grew in confidence and in their understanding of how theoretical processes worked when applied in 
International Journal of Child, Youth and Family Studies (2013) 3.1: 409-432

practice; jurors experienced the powerful sensation of being heard and having their views listened to and valued; mentors and other experienced practitioners were prompted to re-examine their own perceptions and reflect on ways in which they may learn from younger and less inhibited enthusiasts of deliberative democracy. The final word comes from one young participant who observed, "There are massive problems in the world - if people with authority can go with young people on their journey in a positive way, that's great.”

\section{Finland: Dialogue Day Convening Young People with Decision-makers}

A project was conducted in Finland in 2008 to evaluate the possibility of giving young people influence in municipal decision-making (Gretschel, 2009). It was financed by the Ministry of Education and coordinated by Allianssi, a Finnish service and lobbying organization for youth work. In the project, a new participatory forum, Dialogue Day, was created. This particular case study demonstrates how dialogue between young people and decision-makers can be achieved in effective and pleasing ways.

Dialogue Day between young people and decision-makers was explicitly designed to be carried out in "the spirit of deliberation" (Eskelinen et al., 2012, p. 78). This can be seen in different aspects of Dialogue Day. First, it is open to all young people. The ideal composition is from 30 to 50 young people. These participants include active young people from youth councils, student unions, youth organizations, and youth centres, along with young people who are not active in any official organization. During the first half of the Dialogue Day young people deliberate amongst themselves; decision-makers join them later. Ideally around 10 decisionmakers, mainly local politicians and administrators relevant to the theme of the Dialogue Day, would take part.

Facilitation is an important component of Dialogue Day. Trained facilitators have a strong role in supporting youth participants throughout. By using different methods of facilitation every young person is given an opportunity to express his or her opinion. During Dialogue Day facilitators ensure that young people have equal opportunities to speak compared to decision-makers (Gretschel, 2009). Additionally, facilitators press decision-makers to respond appropriately to young people’s questions.

The young participants learned much throughout the Dialogue Day to inform their deliberation. In addition to answering questions, an information package is provided to all participants. Also, a detached authority, such as a scholar, may give a presentation introducing the theme of the Dialogue Day (Pipatti, 2012). Finally, a real influence in relation to policymaking is sought. The objective is to have a concrete response from decision-makers for every suggestion the young participants make. Decision-makers either say they will react to the suggestion or, if they will not, give justifications for their negative decision. If the response to a suggestion is positive, decision-makers decide who will take responsibility for the issue, on what timeline, how young people can be part of the process, and how the results will be monitored (Gretschel, 2009).

The process of the Dialogue Day begins when the young people arrive in the morning and are first introduced by the facilitators to the Dialogue Day and its objectives. Participants begin 
to get acquainted with each other and with the facilitators. After the introductions, information relevant to the theme is presented. For the rest of the morning young participants work in small groups. The objective of the discussions is to choose four to six specific topics from the main theme to be discussed together in more detail with the decision-makers in the afternoon. Importantly, the topics to be discussed between young people and decision-makers are then decided by young people themselves. This ensures that issues discussed with decision-makers will be those that are important to young people (Eskelinen et al., 2012).

After the lunch break, the young people continue with a coaching session, during which they are assisted to generate concrete questions, statements, and suggestions about their selected topics. In a similar fashion, the decision-makers participate simultaneously in a coaching session of their own. Facilitators explain the objective of the event to the decision-makers, who have a brief discussion of their own on the theme of the Dialogue Day. For the rest of the day, young people and decision-makers join in a facilitated discussion that follows an argumentation protocol. First, one of the young participants asks a question, makes a statement, or presents a suggestion, after which it is discussed and a decision made whether it will be accepted or declined. When a suggestion is accepted by the decision-makers, actions are decided on and committed to (Gretschel, 2010). Young participants follow taking turns with the next question, statement, or suggestion, and dialogue continues until the end of the day. Dialogue Day ends with a plenary circle where all participants, both young people and decision-makers, are invited to reflect openly about the event (Gretschel, 2009).

The experiences on Dialogue Days have been positive. In 2008, 18 Dialogue Days were implemented and evaluated as part of a study, each in a different municipality. In total, 302 young persons and 158 decision-makers participated. Feedback from young people and decisionmakers was mostly positive. After having deliberated with young people, decision-makers often made a commitment to take young people's suggestions forward (Eskelinen et al., 2012). However, it is very important that decision-makers begin to act immediately after the Dialogue Day. Otherwise the likelihood increases that the promises made in the event will be forgotten (Gretschel, 2009). As a positive outcome, encounters between young people and decision-makers also increased trust in the young people's abilities and willingness to participate on the part of the decision-makers (Eskelinen et al., 2012).

It should be noted that there are also negative examples where a few individual decisionmakers have placed little or no value on the engagement of young people because, for example, in their opinion young people would be self-seeking and ultimately not really interested in public participation or in influencing decision-making (Gretschel, 2010). However, on the contrary, it seems that young people were willing to take on responsibility in both the decision-making and also in the implementation of these decisions. They did not just make demands on the decisionmakers; they were hoping to be part of the process, for example by working together with adults in a community effort to make the suggestions come true.

Gretschel (2010) defines Dialogue Day activities that engage young people with decisionmakers as a reciprocal "competence test” (p. 165). Decision-makers judge whether young people are capable of making sense of the issues and responding maturely. Young people, on the other hand, judge whether decision-makers take them seriously as worthy collaborators. In the end, the 
International Journal of Child, Youth and Family Studies (2013) 3.1: 409-432

choice is for young people and decision-makers to "try to find each other or to continue miscommunication” (p. 165). Dialogue Days between young people and decision-makers continue to be conducted in different municipalities in Finland. For example, in the spring of 2012 the Vaasa region implemented a Dialogue Day to which young people and decision-makers from eight municipalities were invited to simultaneously participate (Pipatti, 2012). The initiative arose from the Vaasa youth council with the aim of giving a voice to young people to have an impact on the region's future.

\section{Canada: Policy Reform and Inclusive Governance in Indigenous Communities. Use of Participatory Action Research for the Empowerment and Emancipation of Youth with Special Needs}

This case study is the product of a change process that was developed and implemented in an Indigenous territory in Canada. This case study illustrates the importance of identifying opportunities to include youth and their familiies in deliberation platforms in order to reform policy and develop more effective and responsive programs. Key aspects of implementing this change process are presented from a facilitator's point of view. Deliberative democracy was chosen as the process for this event because the vision was to create a safe, non-hierarchical environment that could impact mental models and paradigms with regard to community services and special needs.

The idea of facilitating a dialogue was initiated by a community organization concerned with the early development of children in the territory, specifically parents of children with special needs. The organization members had been working together for over a decade with a local group of youth and parents who were concerned with the future of special needs within the territory. The parents' dream was for their children to have the right opportunities. The facilitator was approached in 2011 to help design a process to increase the participation of youth and families in shaping the future of people with special needs in the region, and more specifically with the aim of improving their overall access to social services. Simultaneously, on a local television show, the chief of the territory publicly suggested convening a group of service providers, community members, youth, and parents to implement a collective dialogue around special needs. This provided the perfect opportunity for starting the change process.

The first priority in designing the process was to work within Indigenous world views and tailor approaches to include the community as a whole. Within three months, working with the local organization and an advocacy group, around 20 influential actors in the field of special needs committed to attending public deliberation meetings to reflect, learn, and act for the betterment of individuals with special needs. The main motivation for attending identified by these actors was to be able to interact and connect with community members.

The process began with the implementation of an action research strategy to assess the current situation on the reserve in the area of special needs. This initial step offered essential information that informed the design of the dialogue process as well as the principles that guided the deliberations. Information gathered during this phase was related to: (a) the nature of relationships among potential participants, (b) the level of collaboration among interested community groups, (c) the readiness for change and action, (d) group views about building 
International Journal of Child, Youth and Family Studies (2013) 3.1: 409-432

collaborative partnerships, (e) the past experiences with facilitators, (f) the past experiences with dialogue processes, (g) the past initiatives toward special needs, (h) what worked and what did not work with respect to those past initiatives, (i) the challenges and strengths as a group, (j) the composition of groups (homogenous or heterogeneous), $(\mathrm{k})$ the nature of dialogue among and between groups, (l) the type of expectations from the different groups, and (m) the feasibility of subjects for discussion.

Following the initial asssesment, a series of facilitated dialogues was implemented to identify possible actions that would build upon collaboration and interdependency. The basic principle in the dialogues was that everyone could contribute with their experiences and knowledge. It was important to involve elders, parents, youth, and other important actors in the community such as the chief of the council and directors of health institutions. The two immediate objectives for the process included the design of a dialogue event in which participants were able to establish relationships and shape together the notion of collaboration. This dialogue process was an important stepping stone for this community's movement toward collaborative governance around special needs.

For the success of this dialogue, it was important to strengthen relationships between the different actors by building trust and getting to know one another. During the first interactions, participants encountered themselves in a literal dance in which they were able to explore boundaries. During the initial stages of the process, there was an increased need for tangible results. The group needed a facilitator who could guide the group toward results and actions. The group engaged an external, independent party able to facilitate and mediate dynamics among all participants. The facilitator was responsible for generating the proper conditions and environment for productive and welcoming interactions.

Two different methodologies were used to manage the dynamics among participants during the different meetings and to guide conversations toward possible actions. The first methodology was the "transitional approach”' of Harold Bridger (2001). It helped to recognize and manage the hierarchical backgrounds of people and institutions, in addition to affording youth a safe space to express themselves and contribute to the conversation. A second methodology, “appreciative inquiry” (Cooperrider, Whitney, \& Stavros, 2008), offered a structure to engage youth from all paths and backgrounds to be part of inclusive, proactive conversations. Essentially, appreciative inquiry is about "changing attitudes, behaviours, and practices through appreciative conversations and relationships - interactions designed to bring out the best in people so that they can imagine a preferred future together” (p. 51).

For the dialogue event, 20 people from different parent and youth groups, community organizations, political leaders, and influential decision-makers gathered in the board room of a local health institution. During the change process, youth and families were able to share their stories and leave behind decades of segregation and frustration. It was a healing process for many who were able to participate and shape the future of special needs in their community. Managers and political leaders were able to engage in a process that generated trust and hope. It was captivating to see first-hand the benefit of working in partnership with community members. Through the application of deliberative democracy, all participants were able to develop 
International Journal of Child, Youth and Family Studies (2013) 3.1: 409-432

meaningful relationships with each other and move into the future, not as individuals in isolation but as a collaborative team.

The key for success in this case study was the capacity to establish non-hierarchical processes and meetings that placed a special emphasis on the inclusion of youth and their parents. This was important because of the complex history that had left many participants living in relative exclusion and segregation. For this reason, deliberative democracy proved to be an excellent methodology to generate trust around the whole process.

\section{United States: Young Adults Deliberating on Planning for Pandemic Influenza}

This case study illustrates a more traditional form of deliberation, the mini-public in which participants generally reflect the communities they are from. It is a mixed-age forum in which youth are asked to engage as equal participants with adults of all ages. In this example, the impact of deliberation on youth opinions of the process and of the subject matter is explored. The case study is presented in a more traditional format with evaluation results used to illustrate how youth voice differs or mirrors that of adult counterparts in mixed-age forums.

From 2005 to 2010 the United States Centers for Disease Control (CDC), in partnership with other state and local government entities, sponsored six public engagement projects related to planning for pandemic influenza (Keystone Center, 2007; University of Nebraska Public Policy Center, 2009). Deliberative models were used in each of the projects in diverse locations across the United States. Each project included participants representing a mix of ages, and featured careful planning, professional facilitation, and evaluation. There have been few studies conducted to specifically identify the impact of deliberation on youth opinions when the age groups are mixed. Lessons learned from five of the in-person deliberations hosted as part of the CDC projects offer a glimpse of the differential impact for young adults (ages 18 to 24) as compared to all other age groups.

Each of the in-person deliberations was facilitated by the same professional group so the approach used to engage participants was consistent over time. Facilitators designed and executed a similar format for each of the deliberations. All participants began by completing a pencil and paper questionnaire capturing demographics and probing their existing knowledge of the deliberation topic, social values, and trust in different levels of government. Officials welcomed participants and provided an overview of the policy issue and the objectives for the deliberative process. An expert or panel of experts presented information to the entire group about the deliberation topic, and then participants seated at tables in mixed-age groups were presented with key questions of interest to the organizers and asked to deliberate and report their results to the larger group. Participants were asked to complete a second questionnaire at the end of the event that included all the questions from the first one plus additional questions about the process.

The goal of local and national organizers was to attract participants who represented diverse points of view and perspectives so the deliberative discussions were productive. Participants of all ages, including those between the ages of 18 and 24, were recruited by organizers in an attempt to mirror the census proportions for age, race, and ethnicity in the local 
area. In each of these events, the young adult age group ended up being underrepresented. The first challenge for organizers wishing to hold mixed-age deliberations is to use recruiting strategies that appeal to age groups differentially. Participants were asked how they learned about the deliberation. Youth reported finding out about it most often from friends, family, or through school sources. They were then asked what made them decide to participate. Comments generally clustered around opportunities to enhance knowledge related to career training, personal interest in the topic, and a desire to influence policy. Several youth participants directly attributed their participation to the stipend they received at the end of the event.

Organizers assumed that participants would come to the deliberative event with varying levels of knowledge about influenza and pandemics. Presentations by experts were designed to level out the amount of knowledge participants had before they began to deliberate. The absolute knowledge increased from the beginning to the end of the day for all age groups including youth. In one deliberation, the youth were less knowledgeable than older adults about influenza both before and after the event, $F(1,811)=6.404, p=.012$. In another deliberation, the knowledge gained by youth was magnified and youth showed a greater knowledge increase overall than older adults, $F(1,184)=4.840, p=.029$. We were not able to tease out the degree to which these changes in knowledge were due to the information presented versus actually participating in the discussions with diverse viewpoints. Controlled studies may increase understanding about which aspects of deliberation influence youth the most.

Another area probed by the questionnaire was social values. These questions involved weighing personal and societal values in the deliberation prior to formulating recommendations. In three of the five deliberations there were significant differences detected between young people and older adults in the area of social values. In comparison to older adults, at the end of the deliberation, young people rated freedom, equality, and utilitarianism higher, and rated safety and security lower. These results were not surprising, and they demonstrate the need to include youth in deliberative processes to give voice to the spectrum of perspectives related to policy decisions.

Another area probed across four of the five deliberations was trust in government. Participants were asked who they trust to make decisions about influenza planning and resource allocation. Two of the deliberations resulted in significant differences between youth and older adults about who they trust to make these decisions. In both cases, youth were more likely than adults to decrease trust of governmental entities perceived as distant (e.g., federal government agencies) while increasing trust of those closer (e.g., local public health districts). Youth were also more likely than older adults to increase support for individuals making decisions about social distancing options rather than governmental entities. In general, the more knowledge participants had about a topic, the more likely they seemed to be to move their preference for control from a higher to a lower level of government.

In three of the pandemic influenza deliberative processes there were significant differences based on age. For example, in two events, young adults had a different view from older adults about who should be vaccinated in an influenza pandemic when vaccine is limited. Youth were less likely than older adults to view minimizing social disruption, ensuring public safety, and protecting people from side effects as important factors to consider in policy 
International Journal of Child, Youth and Family Studies (2013) 3.1: 409-432

development. In a deliberative process on community control measures in the event of a pandemic, youth were less willing to accept measures such as isolating ill persons at home, cancelling events where large groups of people are expected to gather, and not allowing children to congregate outside of schools.

The evaluation also assessed perceptions about the quality of the processes. In two of the events there were significant differences in quality ratings based on age. Young adults rated the deliberative processes significantly lower than older adults on a number of dimensions. Youth were more likely to believe that one or a few people dominated the discussion and were less likely to think (a) the discussion was fair to all participants, (b) the discussion helped them understand the tradeoffs involved, (c) the participants represented a variety of perspectives, (d) the process produced a valuable outcome, and (e) that officials will use their input in their decisions. These results indicate the deliberative process was perceived as less successful by young adults. It is unclear whether the lower ratings by youth were the result of the process being designed more for older participants or whether young adults felt underrepresented in the process. The evaluation results demonstrate the need to design processes, particularly those that involve both youth and adults, to ensure the voice of youth are valued and heard.

The ultimate question was whether policy-makers actually used the information from the deliberations. The evaluation attempted to trace use of information through local, state, and federal agencies by interviewing key decision-makers. The information flow was very difficult to document because decision-makers were often reluctant to be interviewed and for those that did agree, they sometimes had difficulty accurately assessing the weight of different processes and key information (e.g., agency interests, expert recommendations, citizen input) used to make decisions. The extent to which the decision-makers relied specifically on youth input from this process was thus impossible to assess. When we traced the path of influence the actual report from the event had on decision-makers, we discovered that individuals with direct responsibility for the events read and knew about the report contents, but higher level decision-makers knew only what was provided to them by the lower level bureaucrats. In many cases this was a onesentence description of results extrapolated from the overall process to meet a specific need for information. Probably the biggest impact for decision-makers was for those who actually attended the deliberation events as experts. They reported being moved by the seriousness that participants gave their deliberations, the diversity of opinion, and the coalescing of recommendations based on shared conversation.

Through these processes we learned that strong evaluation can potentially elevate youth voices in mixed-age group deliberations by pointing out areas of agreement or discord with the opinions of other age groups. Through the evaluation process, we determined youth offer fundamentally different perspectives from their adult counterparts. Deliberative processes that do not include youth and young adults risk excluding this perspective from policy decisions. The process of deliberative democracy presents an opportunity for involving youth in a forum where they are on equal footing with older adults; however, if youth are underrepresented there is a possibility that the voice may not be heard. More inquiry is required to identify the impact of mixed-age deliberations on youth opinions versus engaging youth in groups with more homogeneity of age. The CDC deliberations surrounding pandemic influenza and vaccine allocation were national in scope, differing from smaller municipal engagement projects only by 
International Journal of Child, Youth and Family Studies (2013) 3.1: 409-432

the policy target. Each deliberation session involved local organizers working in concert with national leaders to recruit participants for each event. Inadequate representation of youth became a local and national concern. Novel ways of engaging youth were tested in other CDC-sponsored public engagement projects that were not deliberative (on-line gaming; on-line dialogue). Although they hold promise for future youth engagement, the face-to-face deliberative model of dialogue may be one of the optimal vehicles to increase understanding across age groups while garnering recommendations based on shared dialogue.

\section{Discussion}

In relation to deliberative youth participation, models of inclusiveness represented in the case studies - young people deliberating together with adults and young people deliberating with each other - have their prospects and challenges. In mixed-age deliberation young participants will hear perspectives from other age cohorts and vice versa. As a result, for example, empathy and solidarity between generations may be developed (Morrell, 2010) and the risk of group polarization may decrease (Sunstein, 2000). However, traditional mini-publics can tacitly concede to prevailing imbalances of power, wealth, and education (Sanders, 1997). As a result some voices, such as those from young people, may be minimized during mixed-age deliberations. Enclave deliberation has, then, the potential for creating spaces for disempowered or marginalized people (Sunstein, 2000; Karpowitz et al., 2009). Naturally, it also matters if the topic of the deliberation is an issue that touches the whole society or only young people. For example in deliberation on pandemic influenza, as the topic was owned by the whole society, it was natural to opt for mixed-age deliberation. The deliberative democracy model is time and resource intensive but could add a level of informed discourse that will potentially benefit decision-makers, particularly those that actually attend the deliberation.

Deliberative youth participation situates naturally within wider deliberative systems. However, there is a danger that deliberative youth participation events could become unconnected in relation to wider deliberations or systems of deliberation designed to inform policy. To avoid this, the relationships between different kinds of deliberative mechanisms need to be constantly nurtured with careful planning so everyone's voices, from youngest to oldest, are heard in a democracy.

Planning and holding deliberative processes with youth poses challenges. First, it is important to remember the complex diversity within the youth population. As was the case with the example of deliberation in an Indigenous community, a special focus is needed to ensure the inclusion of the most marginalized, such as youth with special needs, to achieve an authentic inclusivity. Second, when implementing mixed-age deliberation in which young people deliberate with adults, it is important for facilitators to ensure that young people become equal participants in the deliberation, for example by seeing that young people are not dominated by adults when taking turns to speak.

Youth participation in decision-making can be messy. It is time consuming; it may require the adaptation of traditional data gathering techniques and processes to facilitate youth involvement; and it may produce results that differ from adult inputs. Decision-makers who wish to incorporate youth participation in their work often rely upon specialists with expertise in and 
access to youth to organize and garner youth voice for them. This can mean that the only youth who end up participating are those engaged with the specialist. Policy level decisions are routinely informed by input from adults who reflect the population of interest, but the intentional inclusion of youth voices is not considered routine by most decision-makers. One of the challenges for decision-makers is to consider which decisions could benefit from youth participation, then intentionally plan for youth inclusion.

Before youth can meaningfully participate in policy level decision-making they must have a sense they are empowered and have a structured opportunity to participate (Watts \& Flanagan, 2007). This sense of agency and empowerment for youth is influenced by their experience with authorities, relationships with adults, and perceived social and economic status. The challenge to policy-makers is to increase personal agency (sense of control) in part by structuring participation in ways that empower youth. This may be particularly challenging for agencies that view youth as passive service recipients.

The adult work world often is structured to accept input during traditional business hours. Involving youth in decision-making requires time adjustments to accommodate the demands placed on youth related to school, work, family, friends and extracurricular activities. Many youth schedules are tighter and more inflexible than those of the decision-makers who hope to involve them. The location of the event is also an important factor influencing the level of youth participation. For example, holding a meeting at a location associated with authority may not be comfortable for youth. The physical location is often clouded by its social environment and connotations that can challenge trusting communication (Cockburn, 2007).

Involving youth in planning and implementing the event can help ensure a welcoming environment and productive process for youth participation; however, involving youth in the planning process has its own challenges. Time and space accommodations apply to planning as well as the event. Challenges in language are commonplace when decision-makers ask for youth participation. For example, the problem or decision faced at the policy level may make perfect sense when posed to an adult, but jargon, nuanced words, and professional language may not convey the same message to the children or youth who are being asked to participate in the decision-making.

There are challenges related to the dialogue and the creative tension produced by the purposeful attempt to make decisions collaboratively. This creative tension can be present in brainstorming sessions or in deliberations, and is usually outsourced by the "process of information exchange created between people” (Morgan, 2007, p. 83). Although it is important to motivate youth and adults to explore alternatives creatively and collaboratively, this process can represent a source of conflict; so it is important to have tools and structures available for the effective management of these dynamics.

Finally, as in any kind of public deliberation, it is often difficult to ascertain the effectiveness of deliberative youth participation in actually influencing policy-making. We propose that a virtuous cycle be created to encourage effective deliberation of young people. This virtuous cycle begins with the existence of "process champions" and "enabling leaders" (Carson \& Hart, 2005). Process champions are people who have knowledge of deliberative 
International Journal of Child, Youth and Family Studies (2013) 3.1: 409-432

mechanisms, youth participation, and facilitation. Most naturally these people would be skilled youth workers. Enabling leaders are people who support the implementation of deliberative processes and commit themselves to act on the recommendations developed in the deliberation. Process champions and enabling leaders encourage young people to participate by creating a safe space for deliberative youth participation. By furthering the actual influence of deliberation, enabling leaders empower youth. As a result, the confidence of young people in the processes of public participation increases, and they become more active participants in civil society. A virtuous cycle is created. 
International Journal of Child, Youth and Family Studies (2013) 3.1: 409-432

\section{References}

Addis, A. (2007). Constitutionalizing deliberative democracy in multilingual societies. Berkeley Journal of International Law, 25(2), 101-148.

Bächtiger, A., Niemeyer, S., Neblo, M., Steenbergen, M. R., \& Steiner, J. (2010). Disentangling diversity in deliberative democracy: Competing theories, their blind spots and complementarities. The Journal of Political Philosophy, 18(1), 32-63.

Battistoni, R. (2004). Teaching high-schoolers participatory democracy. Education Digest: Essential Readings Condensed for Quick Review, 70(3), 56-58.

Bennett, W., Wells, C., \& Freelon, D. (2009). Communicating citizenship online: Models of civic learning in the youth web sphere. Seattle, WA: Center for Communication and Civic Engagement.

Bridger, H. (2001). The working conference design. In G. Amado \& A. Ambrose (Eds.), The transitional approach to change (pp. 137-160). London: H. Karnak.

Carson, L. (Ed.). (2003). Consult your community - a handbook: A guide to using citizens' juries. Retrieved from http://www.activedemocracy.net/articles/cj_handbook.pdf

Carson, L. (2010). Taking control: Young people convening Australia’s first youth jury. In W. Linds, L. Goulet, \& A. Sammel (Eds.), Emancipatory practices: Adult/youth engagement for social and environmental justice (pp. 109-121). Rotterdam/Boston/Taipei: Sense Publishing.

Carson, L., \& Hart, P. (2005, August). What randomness and deliberation can do for community engagement. Paper presented at International Conference on Engaging Communities, Brisbane, Australia. Retrieved from http://www.activedemocracy.net/articles.htm

Carson, L., \& Hartz-Karp, J. (2005). Adapting and combining deliberative designs. In J. Gastil \& P. Levine (Eds.), The deliberative democracy handbook (pp. 120-138). San Francisco, CA: Jossey-Bass.

Carson, L., \& Martin, B. (1999). Random selection in politics. Westport, CT: Praeger.

Carson, L., Sargant, C., \& Blackadder, J. (2004). Consult your community: A guide to running a youth jury. Retrieved from http://www.activedemocracy.net/parrayouth/docs/youthjuries-handbook.pdf

Chambers, S. (2003). Deliberative democratic theory. Annual Review of Political Science, 6(1), 307-326. 
International Journal of Child, Youth and Family Studies (2013) 3.1: 409-432

Clifford, S. (2012). Making disability public in deliberative democracy. Contemporary Political Theory, 11(2), 211-228.

Cockburn, T. (2007). Partners in power: A radically pluralistic form of participative democracy for children and young people. Children \& Society, 21(6), 446-457.

Cooperrider, D., Whitney, D., \& Stavros, J. (2008). Appreciative inquiry handbook: For leaders of change (2nd ed.). Brunswick, OH: Crown Custom Publishing.

Crosby, N. (2003). Healthy democracy: Empowering a clear and informed voice of the people. Edina, MN: Beaver's Pond Press.

Dryzek, J. (2010). Foundations and frontiers of deliberative governance. New York: Oxford University Press.

Edelmann, N., Krimmer, R., \& Parycek, P. (2008). Engaging youth through deliberative eparticipation: A case study. International Journal of Electronic Governance, 1(4), 385399.

Elstub, S. (2010). The third generation of deliberative democracy. Political Studies Review, 8(3), 291-307.

Eskelinen, T., Gretschel, A., Kiilakoski, T., Kiili, J., Korpinen, S., Lundblom, P., et al. (2012). Lapset ja nuoret subjekteina kunnallisessa päätöksenteossa [Children and youth as subjects in municipal decision making]. In A. Gretschel \& T. Kiilakoski (Eds.), Demokratiaoppitunti [Lecture on democracy] (pp. 35-91). Helsinki, Finland: The Finnish Youth Research Society.

Feldmann-Wojtachnia, E., Gretschel, A., Helmisaari, V., Kiilakoski, T., Matthies, A-L., Meinhold-Henschel, S., et al. (2010). Youth participation in Finland and Germany: Status analysis and data based recommendations. Retrieved from http://www.cap.lmu.de/download/2010/youth-participation.pdf

Ferman, B. (2005). Youth civic engagement in practice: The youth VOICES program. The Good Society, 14(3), 45-50.

Frank, K. (2006). The potential of youth participation in planning. Journal of Planning Literature, 29(4), 351-371.

Friedman, W. (2006). Deliberative democracy and the problem of scope. Journal of Public Deliberation, 2(1), Article 1. Retrieved from http://www.publicdeliberation.net/jpd/vol2/iss1/art1/

Fung, A. (2003). Survey article: Recipes for public spheres: Eight institutional design choices and their consequences. The Journal of Political Philosophy, 11(3), 338-367. 
International Journal of Child, Youth and Family Studies (2013) 3.1: 409-432

Gretschel, A. (Ed.). (2009). Nuorten vaikutusmahdollisuuksien arviointi 2008 [Evaluation of youth influence]. Helsinki, Finland: Allianssi ry.

Gretschel, A. (2010). Sanat ja teot kuntapäättäjien ja nuorten keskusteluissa [Words and actions in discussions between municipal decision makers and young people]. In A.-H. Anttila, K. Kuussaari, \& T. Puhakka (Eds.), Ohipuhuttu nuoruus? [The encountered youth] (pp. 155-167). Helsinki, Finland: The Finnish Youth Research Society, the National Institute for Health and Welfare, Advisory Council for Youth Affairs.

Gutmann, A., \& Thompson, D. (2004). Why deliberative democracy? Princeton, NJ and Oxford, UK: Princeton University Press.

Habermas, J. (1999). Moral consciousness and communicative action (6th ed.). Cambridge, MA: MIT Press.

Hart, D., \& Donnelly, T. (2007). High school community service as a predictor of adult voting and volunteering. American Educational Research Journal, 44(1), 197-219.

Hendriks, C. M. (2006). Integrated deliberation: Reconciling civil society’s dual role in deliberative democracy. Political Studies, 54(3), 486-508.

Huber, M., Frommeyer, J., Weisenbach, A., \& Sazama, J. (2003). Giving youth a voice in their own community and personal development: Strategies and impacts of bringing youth to the table. In F. Villarruel, D. Perkins, L. Borden, \& J. Keith (Eds.), Community youth development: Programs, policies, and practices (pp. 297-324). Thousand Oaks, CA: Sage Publications.

Karpowitz, C. F., Raphael, C., \& Hammond, A. S. (2009). Deliberative democracy and inequality: Two cheers for enclave deliberation among the disempowered. Politics \& Society, 37(4), 576-615.

Keystone Center. (2007). The public engagement project on community control measures for pandemic influenza. Retrieved from https://www.keystone.org/images/keystonecenter/sppdocuments/2011/H1N1/novel\%20h1n1\%20vaccine\%20evaluation\%20final.pdf

Levine, P. (2007a). The future of democracy: Developing the next generation of American citizens. Medford, MA: Tufts University Press.

Levine, P. (2007b). A public voice for youth: The audience problem in digital media and civic education. In W. Lance Bennett (Ed.), Civic life online: Learning how digital media can engage youth (pp. 119-138). Cambridge, MA: The MIT Press. 
International Journal of Child, Youth and Family Studies (2013) 3.1: 409-432

Mansbridge J., Bohman, J., Chambers, S., Christiano, T., Fung, A., Parkinson, J., et al. (2012). A systemic approach to deliberative democracy. In J. Parkinson \& J. Mansbridge (Eds.), Deliberative systems (pp. 1-26). New York: Cambridge University Press.

Mansbridge, J., Bohman J., Chambers S., Estlund, D., Føllesdal, A., Fung, A., et al. (2010). The place of self-interest and the role of power in deliberative democracy. The Journal of Political Philosophy, 18(1), 64-100.

Matthews, H. (2010). Citizenship, youth councils and young people’s participation. Journal of Youth Studies, 4(3), 299-318.

McLeod, J. (2000). Media and civic socialization of youth. Journal of Adolescent Health, 27(2), 45-51.

Mohamed, I., \& Wheeler, W. (2001). Broadening the bounds of youth development: Youth as engaged citizens. Chevy Chase, MD: Innovation Center for Community and Youth Development.

Morgan, G. (2007). Images of organization. Thousand Oaks, CA: Sage Publications.

Morgan, W., \& Streb, M. (2001). Building citizenship: How student voice in service-learning develops civic values. Social Science Quarterly, 82(1), 154-169.

Morrell, M. E. (2010). Empathy and democracy: Feeling, thinking, and deliberation. University Park, PA: The Pennsylvania State University Press.

Olsson, T. (2007). An indispensable resource: The internet and young civic engagement. In P. Dahlgren (Ed.), Young citizens and new media: Learning for democratic participation (pp. 187-204). London: Routledge.

Pasek, J., Feldman, L., Romer, D., \& Jamieson, K. (2008). Schools as incubators of democratic participation: Building long-term political efficacy with civic education. Applied Developmental Science, 12(1), 26-37.

Peavey, F. (2005). Strategic questioning: An experiment in communication of the second kind. Retrieved from http://www.activedemocracy.net/articles/PeaveyStrategicQuestioning.pdf

Peng, I. (2000). Effects of public deliberation on high school students: Bridging the disconnection between young people and public life. In S. Mann \& J. Patrick (Eds.), Education for civic engagement in democracy: Service learning and other promising practices (pp. 73-86). Bloomington, IN: ERIC/ChESS.

Pipatti, A-M. (2012). Vaasan seudun tulevaisuus nuorten näkökulmasta-loppuraportti [The future of the Vaasa region from the perspective of young people (Final report)]. Vaasa, Finland: City of Vaasa. 
International Journal of Child, Youth and Family Studies (2013) 3.1: 409-432

Raisio, H., \& Carson, L. (in review). Deliberation within sectors: Making the case for sector mini-publics. Manuscript in review.

Raisio, H., Ollila, S., \& Vartiainen, P. (2012). Do youth juries enhance youth political and societal participation? Lessons from the Vaasa experiment. Scandinavian Journal of Public Administration, 15(3), 41-60.

Rubin, B. (2007). “Laboratories of democracy”: A situated perspective on learning social studies in detracked classrooms. Theory \& Research in Social Education, 35(1), 62-95.

Ryan, M. (2010). Productions of space: Civic participation of young people at university. British Educational Research Journal, 37(6), 1015-1031.

Sanders, L. M. (1997). Against deliberation. Political Theory, 25(3), 347-376.

Scherer, S., Neuroth, C., Schefbeck, G., \& Wimmer, M. (2009). Enabling eParticipation of the youth in the public debate on legislation in Austria: A critical reflection. In A. Macintosh \& E. Tambouris (Eds.), Electronic participation: Lecture notes in computer science (pp. 151-162). Heidelberg, Germany: Springer.

Segall, S. (2005). Political participation as an engine of social solidarity: A sceptical view. Political Studies, 53(2), 362-378.

Steiner, J. (2012). Learning to deliberate. In G. M. Carney \& C. Harris (Eds.), Citizens' voices: Experiments in democratic renewal and reform (pp. 3-7). Galway, Ireland: ICSG.

Sunstein, C. R. (2000). Deliberative trouble? Why groups go to extremes. The Yale Law Journal, 110(1), 71-119.

Sunstein, C. R. (2003). The law of group polarization. In J. S. Fishkin \& P. Laslett (Eds.), Debating deliberative democracy (pp. 80-101). Malden, MA: Blackwell Publishing.

Syvertsen, A., Stout, M., Flanagan, C., Mitra, D., Oliver, M., \& Sundar, S. (2009). Using elections as teachable moments: A randomized evaluation of the student voices civic education program. American Journal of Education, 116(1), 33-67.

University of Nebraska Public Policy Center. (2009). Evaluation of novel H1N1 vaccine policy public engagement. Retrieved from https://www.keystone.org/images/keystonecenter/sppdocuments/2011/H1N1/novel\%20h1n1\%20vaccine\%20evaluation\%20final.pdf

Von Burg, A., Von Burg, R., Mitchell, G., \& Louden, A. (2012). Emerging communication technologies and the practices of enhanced deliberation: The experience of Benjamin Franklin Transatlantic Fellows Summer Institute. Journal of Public Deliberation, 8(1). Retrieved from http://www.publicdeliberation.net/jpd/vol8/iss1/art14/ 
International Journal of Child, Youth and Family Studies (2013) 3.1: 409-432

Waldstein, F., \& Reiher, T. (2001). Service-learning and students’ personal and civic development. Journal of Experiential Education, 24(1), 7-13.

Watts, R. J., \& Flanagan, C. (2007). Pushing the envelope on youth civic engagement: A developmental and liberation psychology perspective. Journal of Community Psychology, 35(6), 779-792.

Wells, C. (2010). Citizenship and communication in online youth civic engagement projects. Information, Communication \& Society, 13(3), 419-441.

Wilson, P. A. (2009). Deliberative planning for disaster recovery: Re-membering New Orleans. Journal of Public Deliberation, 5(1). Retrieved from http://www.publicdeliberation.net/jpd/vol5/iss1/art1/

Wolff, J., \& Crockett, L. (2011). The role of deliberative decision making, parenting, and friends in adolescent risk behaviors. Journal of Youth and Adolescence, 40(12), 1607-1622.

Wulff, B. (2003). Creating a sandlot for democracy: The study circles resource center's approach to youth civic engagement. National Civic Review, 92(3), 12-19.

Wyness, M. (2009). Children representing children: Participation and the problem of diversity in UK youth councils. Children, 16(4), 535-552.

Young, I. M. (2000). Inclusion and democracy. Oxford, UK: Oxford University Press.

Youniss, J. (2011). Civic education: What schools can do to encourage civic identity and action. Applied Developmental Science, 15(2), 98-103. 